\title{
Fabrication and Mechanical Charecterization of Cnt Nanocomposites
}

\author{
D. Madhava Reddy, A.Kalyan Charan, Ch.Rakesh \\ Mechanical Engineering Department, K.N.R.C.E.R, Hyderabad
}

\begin{abstract}
The effects of Amine, Epoxide functionalization of multi-wall carbon nanotubes on properties of CNT/epoxy nanocomposites are investigated in this work. Adding CNTs to the matrix is expected to improve the stiffness, toughness, interlaminar shear strength of and many other properties of composites. Functionalization with different amino and epoxide groups of multi-walled carbon nanotubes was achieved and nanotube-reinforced epoxy nanocomposites were prepared by mixing amino, epoxide-functionalized multiwalled carbon nanotubes with epoxy resin. The reinforcement mechanism of amino-functionalized multi-walled carbon nanotubes in epoxy resin was discussed. Interlaminar shear strength (ILSS), Three point bending test and Re-bound hardness tests were used to investigate the mechanical properties of the nanocomposites and functionalization groupings are investigated by Fourier transform spectroscopy (FTIR). Then the results of amine, epoxide group are compared with No-CNT nanocomposite. The results showed that different percentage of amino, epoxide-functionalized multi-walled carbon nanotubes would have different effects on the mechanical properties of the nanocomposites. The amine functionalizes CNT composites are giving good results compare to another samples.
\end{abstract}

Key words: A. Carbon nanotubes, B. Epoxy, C. Mechanical properties

\section{Introduction}

Carbon nanotubes (CNTs) are increasingly attracting scientific and industrial interest by virtue of their outstanding characteristics [1]. Both theoretical and experimental studies have shown that the elastic modulus of carbon nanotube is in the range of 1-5TPa [2]. Such a superior property makes CNTs a promising reinforcing material. The CNT/polymer nanocomposites hold the promise of delivering exceptional mechanical properties and multi-functional characteristics. The potential of employing CNTs as reinforcements has, however, been severely limited because of the difficulties associated with dispersion of entangled CNTs during processing and the poor interfacial interactions between CNTs and polymer. To ensure effective reinforcements for polymer composites, proper dispersion and good interfacial bonds between CNTs and polymer matrix have to be guaranteed [3]. Epoxy resin is the most common class of thermosetting resin used in various applications because of their high tensile strength and modulus, low shrinkage in cure, good chemical and corrosion resistance, high adhesion and dimensional stability [4]. Epoxy resins have been widely used in practical applications such as adhesives, construction materials, composites, laminates and coatings owing to their excellent mechanical properties [5], low cost, ease of processing, good adhesion to many substrates, and good chemical resistance. However, the realization of nanotube-reinforced epoxy resin can only be achieved by solving two main problems: (i) the large contact areas of carbon nanotubes and the relatively strong inter-tube attraction via Vander Waal's forces makes the nanotubes spontaneously bundle together, which making their dispersion in epoxy matrix more difficult and (ii) the poor interfacial adhesion between the raw nanotubes and the matrix influences the reinforcing effect of CNTs [1]. Epoxy based composite materials are being increasingly used as structural components in aerospace and automobile industry due to their excellent high adhesion, low weight , and good chemical corrosion resistance [9]. In recent years, there have been considerable achievements in carbon nanotube reinforced polymer matrix nanocomposites, which show a remarkable enhancement in mechanical properties compared to those of monolithic materials [6]. Most of the existing researches on nanocomposites have mainly focused on the dispersion method of nanoparticles [7]. There have been several ways to make polymer/CNT nanocomposites, including solution mixing, melt blending and melt spinning and situ polymerization [8]. Each of these methods has its advantage and disadvantages. The direct incorporation using chemical methods and by application of shear forces during mechanical powder dispersion process are the popular one. Ultrasound vibration was used to disperse nanoparticles, which also helps to improve the dispersion state of nanopraticles [11]. Many previous studies described the fabrication and characterization of CNT/Epoxy nanocomposites. They investigated the influence of catalytically grown MWCNT's microtexture, structure and surface chemistry on the improvement of the elastic modulus of nanotubes based composites [10]. 


\subsection{Fabrication of material}

\section{Experimental section}

The fabrication of functionalized MWCNTs reinforced Epoxy/Carbon-fiber composites is carried out in various steps. Dispersion of CNTs in epoxy resin takes main role in Nanocomposite fabrication. Probstylesonicator was used for dispersion of CNTs. Appropriate amount of MWCNTs (example: $0.5 \%$ CNTs mean $0.65 \mathrm{gm}$ ) are weighed according to the required percentage and were added to the epoxy (LY556-130gm), then the mixture was stirred using probstylesonicater (sonicator3000 ) for $30 \mathrm{~min}$ to ensure good homogeneity. Here we use on and off method; it means stirred accords $10 \mathrm{sec}$ then it off another $10 \mathrm{sec}$. This we can control in sonicator by programming. If it is stirred continuously CNTs will be destroyed. Ones stirring is completed Hardener (Biphenyl1 -4, 4diamine) was added in to the mixture, and then the mixture was stirred manually for about $10 \mathrm{~min}$. Then we took ten carbon sheets of $150 \times 150 \mathrm{~mm}^{2}$ sheets is arranged in order for applying the mixed resin. After arranging, the prepared resin is applied to each fabric on both sides uniformly with the help of brush. Then a mould is taken in which a Teflon sheet is spread on it. On this Teflon sheet, all the ten fabric are arranged on one above the other. Then a Teflon sheet is again spread on the ten layers and covered with the top plate of the mould. Then this mould is tightened hard using screws for uniform pressing. Then this mould is kept in humidity oven for $2 \mathrm{hrs}$ at $150^{\circ}$. After $2 \mathrm{hrs}$, the mould is allowed to cool to room temperature for 2 to $3 \mathrm{hrs}$. Then the mould is opened to get a fine functionalized MWCNTs reinforced Epoxy/C-fiber composite. Using this method we made $0.25 \%$, $0.5 \%, 1 \%, 2 \%$ amine, epoxide fictionalize MWCNT-Epoxy/Carbon-fiber Nanocomposite.

\subsection{Characterization}

\subsubsection{FTIR spectra}

FTIR spectra collected by a spectrum one FTIR spectrometer. CNTs were mixed with $\mathrm{KBr}$ powder and compressed as pellets for data collection. The spectrum was collected against $\mathrm{KBr}$ background. The nanocomposites were analyzed as films and the spectra were collected against air background. The FTIR spectra for pure CNTs and nanocomposites films were collected as absorbance spectra using 32 scans at $2 \mathrm{~cm}-1$ resolution.

\subsubsection{Three Point bending test}

Flextural load was employed in an instron under three point bend fixture and loading rate was applied according to the specimen dimension as defined in ASTMD-790. The nanocomposite samples were directly cut into $78 \mathrm{~mm} \times 25 \mathrm{~mm} \times 3 \mathrm{~mm}$. At least three different specimens were tested. The flexural strength and flexural modulus results were averaged and the standard error was calculated. Flexural strength $\sigma$ is calculated based on the following equation (1).

$$
\sigma=3 \mathrm{PL} / 2 \mathrm{bd}^{2} .
$$

where; $\sigma$ is the strength in the outer fibers at midspan (MPa), $\mathrm{P}$ is the load at a given point on the load-deflection curve $(\mathrm{N}), \mathrm{L}$ is the support span $(\mathrm{mm}), \mathrm{b}$ and $\mathrm{d}$ are the width and thedepth of beam tested,respectively $(\mathrm{mm})$. The modulus of elasticity (E) is calculated based on the following equation (2).

$$
\mathrm{E}=\mathrm{L}^{3} \mathrm{~m} / 4 \mathrm{bd} \mathrm{d}^{3} \ldots \ldots(2)
$$

Where E shows the modulus of elasticity in bending (GPa), $\mathrm{L}$ is the support span $(\mathrm{mm}), \mathrm{b}$ and $\mathrm{d}$ are the width and the depth of beam tested, respectively $(\mathrm{mm})$, and $\mathrm{m}$ is the slope of the tangent to the initial straight line portion of the load-deflection curve $(\mathrm{N} / \mathrm{mm})$

\subsubsection{Interlaminar shear strength}

The Interlaminar shear strength (ILSS) of the nanocomposite laminates was measured according to ASTM D-2344-00 with the short beam method. Universal tensile testing machine was used for the determination of the ILSS. At least three different specimens were tested. The shear strength results were averaged and the standard error was calculated

\subsubsection{Re-Bound hardness method}

Using Re-bound method I find the hardness number of the materials. The principle of rebound method is dropping a diamond tipped hammer, which falls inside a glass tube under the force of its own weight from a fixed height, onto the test specimen. The height of the rebound travel of the hammer is measured on a graduated scale. 


\subsection{FTIR analysis}

\section{Results and discussion}

FTIR spectra can provide further evidence for the variation in the thermal and mechanical properties of the different samples in terms of their molecular structures. Fig 3.1 shows the FTIR spectra of the amine functionalized MWCNTs. In spectrum, the peaks at $3435 \mathrm{~cm}^{-1}$ and $1030.4 \mathrm{~cm}^{-1}$ are in correspondence to N-H, C-N stretch vibration. From here it can be determined that the surface of the MWNTs contains $\mathrm{NH}_{2}$ group. Figure 3.2 and 3.3 shows the various peaks. Whether it is $0.5 \mathrm{wt} \% \mathrm{CNT}, 1 \mathrm{wt} \% \mathrm{CNT}$ it will show the same trend, because both are having the same functional group

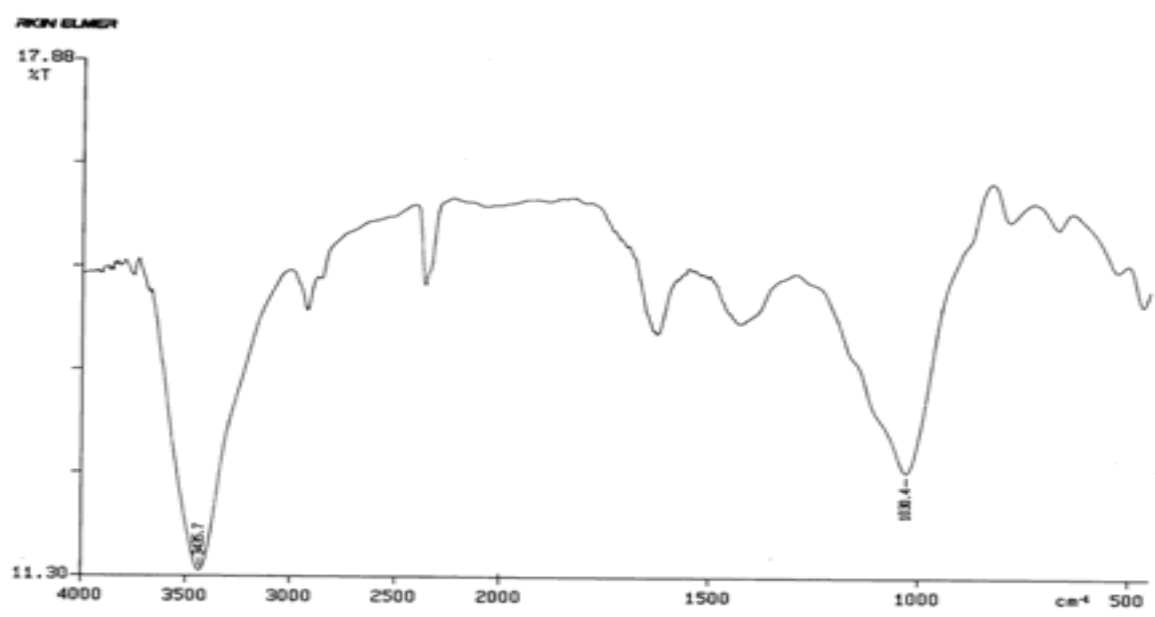

$00 / 05 / 1615$ : 06 chesistry
$Y: 16$ scans, 2.0es-1, smooth

Figure 3.1. FTIR spectra of the amine functionalized MWCNT

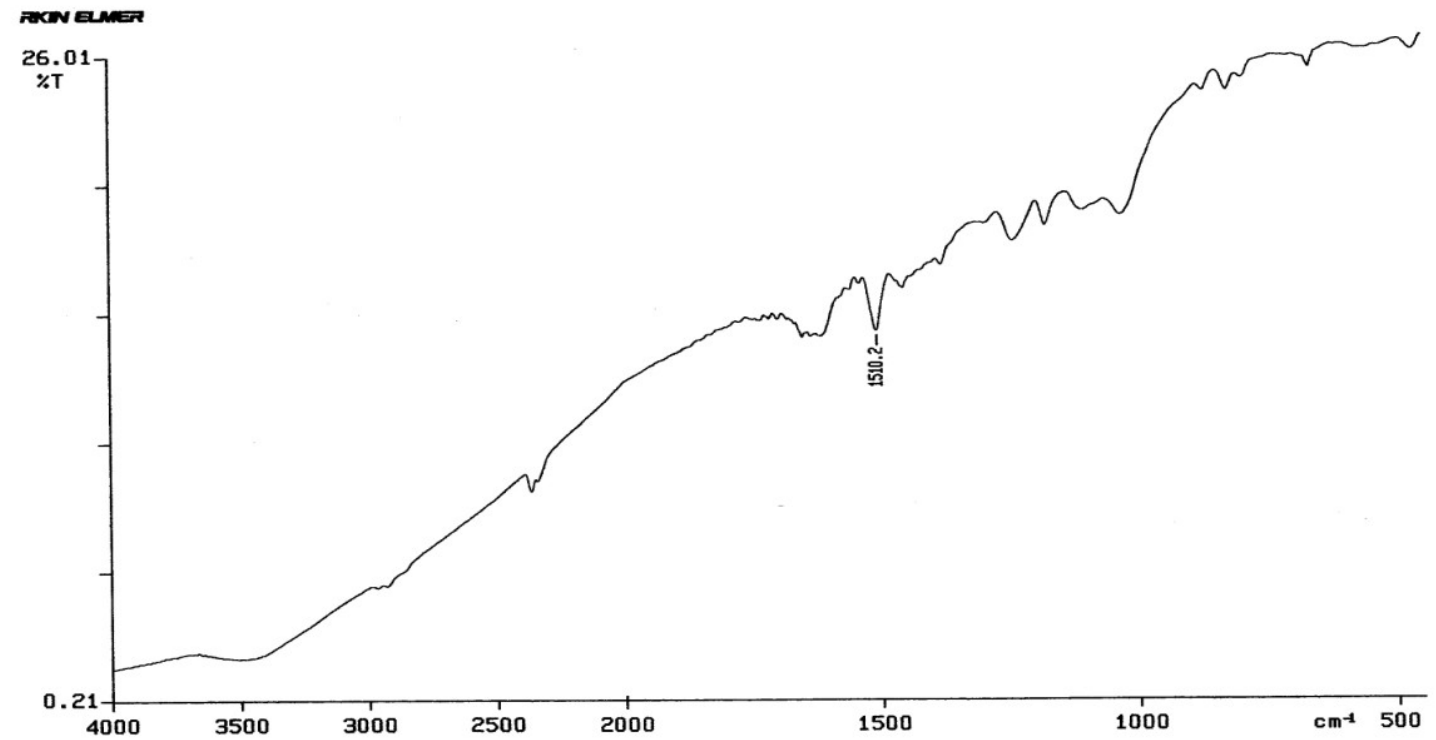

08/05/07 16:20 chemistry

$Y: 16$ scans, $2.0 \mathrm{~cm}-1$, smooth

Figure 3.2. FTIR spectra of the $0.5 \%$ amine functionalized MWCNT composite 


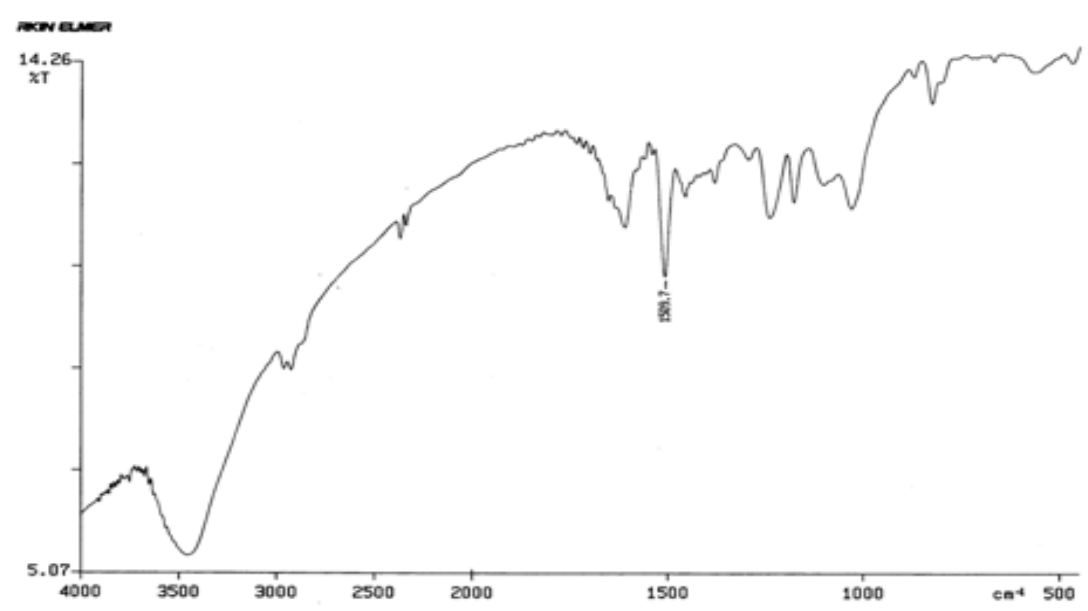

08/05/07 16:17 chemistry

Figure 3.3. FTIR spectra of the $1 \%$ amine functionalized MWCNT composite

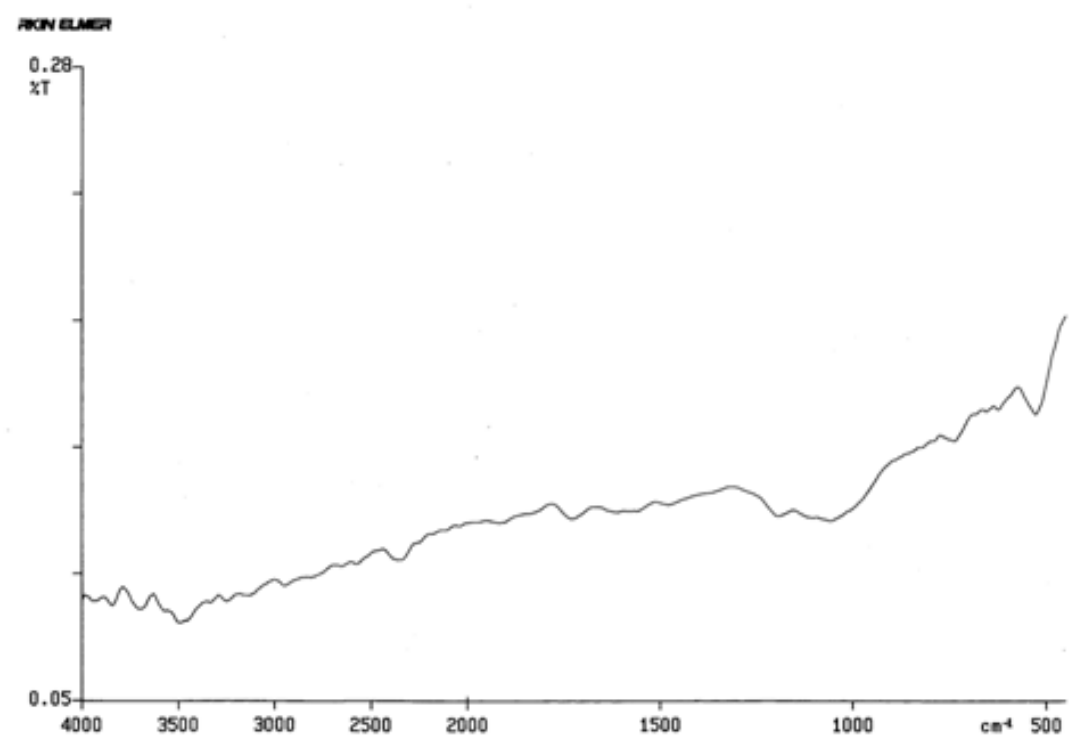

08/05/16 15:02 chenistry

Y: 16 scans, $2.0 \mathrm{~cm}-1$, smooth

Figure 3.4. FTIR spectra of the epoxide functionalized MWCNT

\begin{tabular}{|c|c|c|c|c|c|c|c|c|c|}
\hline & \multicolumn{9}{|c|}{ Sample } \\
\cline { 2 - 9 } & $\mathbf{B}$ & $\mathbf{A}_{0.25}$ & $\mathbf{A}_{0.5}$ & $\mathbf{A}_{1}$ & $\mathbf{A}_{2}$ & $\mathbf{E}_{0.25}$ & $\mathbf{E}_{0.5}$ & $\mathbf{E}_{1}$ & $\mathbf{E}_{2}$ \\
\hline $\begin{array}{c}\text { Mean Flexural } \\
\text { strength } \\
\text { MPa }\end{array}$ & $\mathbf{6 2 3}$ & 703 & $\mathbf{6 6 7 . 7}$ & $\mathbf{6 9 1 . 8}$ & $\mathbf{5 6 9 . 3}$ & $\mathbf{6 8 1}$ & $\mathbf{6 1 9}$ & $\mathbf{6 1 0}$ & $\mathbf{6 2 3}$ \\
\hline $\begin{array}{c}\text { Mean Flexural } \\
\text { Modulus } \\
\text { GPa }\end{array}$ & $\mathbf{5 9 . 9 6}$ & $\mathbf{6 0 . 4 6}$ & $\mathbf{6 1}$ & $\mathbf{6 2 . 5}$ & $\mathbf{5 4 . 9 2}$ & $\mathbf{5 6 . 9 7}$ & $\mathbf{5 0 . 6 6}$ & $\mathbf{5 8 . 7 2}$ & $\mathbf{5 6 . 9 3}$ \\
\hline
\end{tabular}

Table 3.1 Flexural strength and modulus of no CNT, Amine functionalized CNT and Epoxide CNT/C-fiber/Epoxy composites 


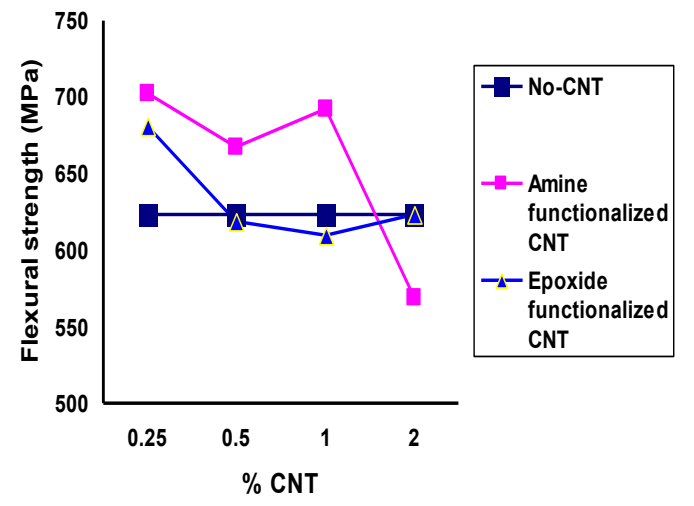

Figure 3.5 Flexural strength comparison between No CNT, Amine functionalized

CNT and Epoxide CNT composites

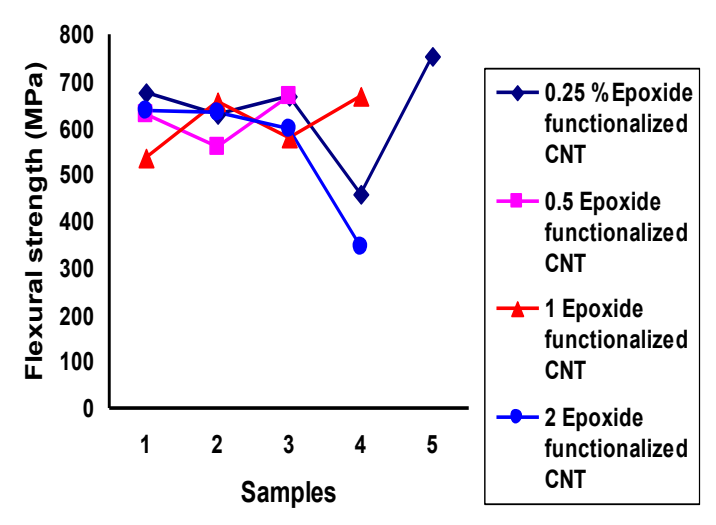

Figure 3.7 Flexural strength comparison between multi samples with same percentage of Epoxide functionalized CNT/C -fiber/Epoxy composite

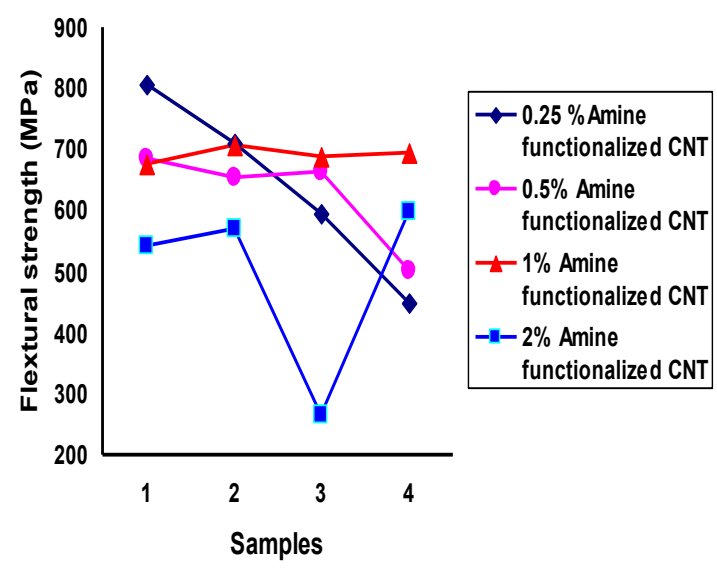

Figure 3.6 Flexural strength comparison between multi samples with same percentage of amine functionalized CNT/C-fiber/Epoxy composite

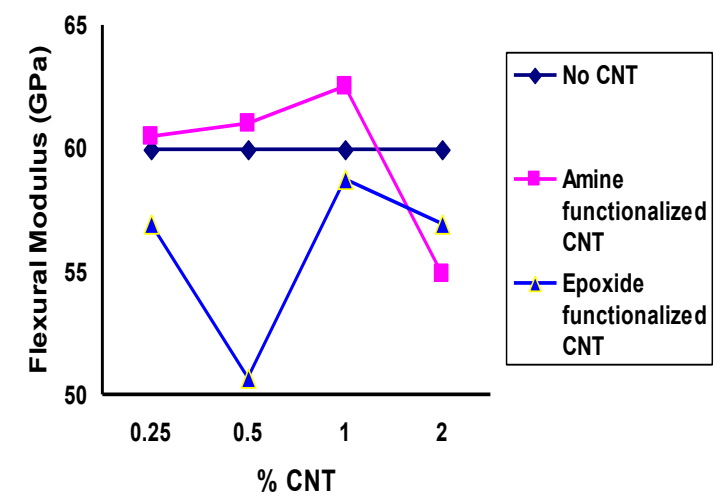

Figure 3.8 Flexural modulus comparison between no CNT, Amine functionalized CNT and Epoxide CNT /C-fiber/Epoxy composites

Moreover, once embedded in the epoxy, there are no chances of getting good repeatability of the trend. Moreover epoxy matrix it self will give it's own trend, it is showing many peaks at 1500 to $700 \mathrm{~cm}-1$ range they are related to $\mathrm{C}$ streching, $\mathrm{C}-\mathrm{H}$ streching etc. Figure 3.4 shows the FTIR spectra of the epoxide functionalized MWCNTs. In spectra there are no peaks. From here it can be determine that the surface of the MWCNTs contain any $\mathrm{CH}_{2}$ group.

\subsection{Flexural strength and modulus results}

Flexural test performed to evaluate the flexural strength and modulus of the materials. Comparison of three different samples with No CNT, amine functionalizes CNT and epoxide functionalizes CNT. When compare between the No CNT composite with amine functionalize CNT composite, amine functionalization $\mathrm{CNT}$ are showing better mean flexural strength. $\mathrm{A}_{2}$ sample showing the less value than the no CNT composite material. In amine functionalized CNT, $\mathrm{A}_{0.25}$ case showing maximum flexural strength. The overall order of the flexural strength found to be $\mathrm{A}_{0.25}>\mathrm{A}_{1}>\mathrm{A}_{0.5}>\mathrm{A}_{2}$. Where as Epoxide functionalization CNT with the No CNT composite, $\mathrm{E}_{0.25}$ only showing the more value remaining is less than the no CNT composite. They are found in the order of $\mathrm{E}_{0.25}>\mathrm{E}_{2}>\mathrm{E}_{0.5}>\mathrm{E}_{1}$. Table 3.1 shows the values of the flexural strength. Amine functionalizes CNT composites flexural strengths are showing better performance than the Epoxide functionalization CNT. The figure 3.5 shows the comparisons between the No CNT composite, amine functionalize and epoxide functionalize CNT composites. And figure 3.6, 3.7 shows the comparison between multi samples with same percentage of CNT.

When compare the flexural modulus between the no CNT composite with amine functionalized CNT composite, amine functionalization CNTs are showing better mean flexural modulus. $\mathrm{A}_{2}$ sample showing the 
less value than the no CNT composite material. In amine functionlization CNT, $\mathrm{A}_{0.5}$ case showing maximum flexural modulus. The overall order of the flexural modulus found to be $\mathrm{A}_{0.5}>\mathrm{A}_{0.25}>\mathrm{A}_{0.5}>\mathrm{A}_{2}$. Where as Epoxide functionalization CNT with the No CNT composite, all samples showing less than the no CNT composite. They are found in the order of $\mathrm{E} 2>\mathrm{E}_{0.25}>\mathrm{E}_{2}>\mathrm{E}_{5.5}$. Table 3.1 shows the values of the flexural strength and modulus.

Amine functionalized CNT composites flexural modulus are showing better performance than the Epoxide functionalization CNT.

\subsection{Inter laminar shear strength results}

Inter laminar shear strength to evaluate the shear strength of the materials. Comparison of three different samples with No CNTs, amine functionalizes CNTs and epoxide functionalizes CNTs.

When compare between the No CNT composite with amine functionalize CNT composite, amine functionalization CNTs are showing better mean shear strength. $\mathrm{A}_{2}$ sample showing the near value to No CNT composite material. In amine functionlization $\mathrm{CNT}, \mathrm{A}_{0.5}$ cases showing maximum shear strength. The overall order of the shear strength found to be $\mathrm{A}_{0.5}>\mathrm{A}_{1}>\mathrm{A}_{0.25}>\mathrm{A}_{2}$. Where as Epoxide functionalization CNT with the no CNT composite, all samples showing the more value than the No CNT composite. They are found in the order of $E_{2}>E_{1}>E_{0.25}>E_{0.5}$. Table 3.3 shows the Inter laminar shear strengths of no CNT, amine functionalize $\mathrm{CNT}$ and epoxide CNT/C-fiber/epoxy composites.

Amine functionalizes CNT composites and Epoxide functionalization CNT both are showing near shear strength values. The figure 3.9 shows the comparisons between the no CNT composite, amine functionalize and epoxide functionalize CNT composites. And figure 3.10, 3.11 shows the comparison between multi samples with same percentage of CNT.

\subsection{Re-Bound hardness method results}

In the present work, Re-Bound hardness test performed to evaluate the hardness number of the materials. Comparison of three different samples with no CNTs, amine functionalizes CNTs and epoxide functionalizes CNTs. Table 3.2 shows the Re-bound hardness number

When compare between the No CNT composite with amine functionalize CNT composite, amine functionalization CNTs are showing better mean hardness number. $\mathrm{A}_{1}$ samples showing the less value than the No CNT composite materials. In amine functionlization $\mathrm{CNT}, \mathrm{A}_{0.5}$ case showing maximum hardness number. The overall order of the hardness number found to be $A_{0.5}>A_{0.25}>A_{2}>A_{1}$. Figure 5.12 shows the Re-Bound $C$ comparison between multi samples with same percentage of amine functionalized CNT/C-fiber/epoxy composite.

When we compare the ILSS test results standard deviation and flexural results, standard deviation is large in flexural results and smaller in ILSS results.

Table 3.5 Re-bound, number of No CNT and Amine functionalized CNT/C-fiber/Epoxy composite

\begin{tabular}{|c|c|c|c|c|c|}
\hline & \multicolumn{5}{|c|}{ Sample } \\
\cline { 2 - 6 } & $\mathrm{B}$ & $\mathbf{A}_{0.25}$ & $\mathbf{A}_{0.5}$ & $\mathbf{A}_{1}$ & $\mathbf{A}_{2}$ \\
\hline $\begin{array}{c}\text { Re- } \\
\text { bound } \\
\text { hardness } \\
\text { number }\end{array}$ & $\mathbf{3 9 . 0 8}$ & $\mathbf{4 2 . 8}$ & $\mathbf{4 3 . 1 6}$ & $\begin{array}{c}37 . \\
5\end{array}$ & $\mathbf{4 2 . 4 1}$ \\
\hline
\end{tabular}

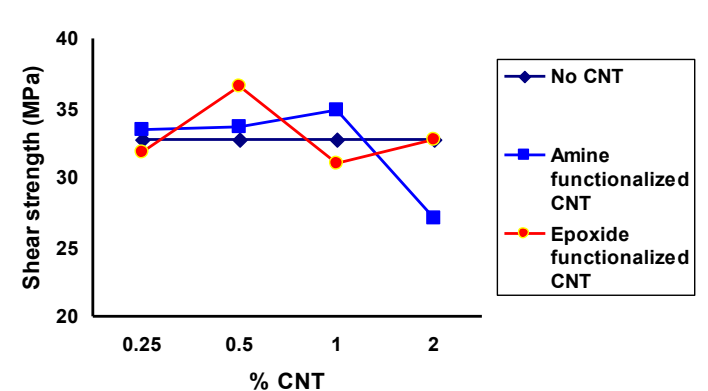

Figure 3.10 Shear strength comparisons between multi samples with same percentage of amine functionalized CNT/C -fiber/Epoxy composite

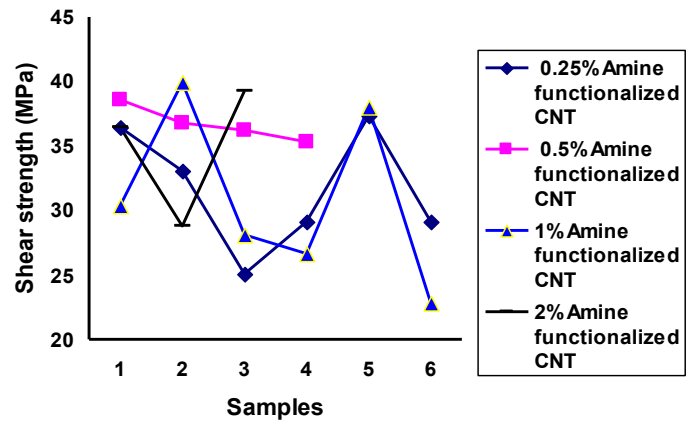

Figure 3.11 Shear strength comparison between multi samples with same percentage of Amine functionalized CNT/C-fiber/Epoxy composite 


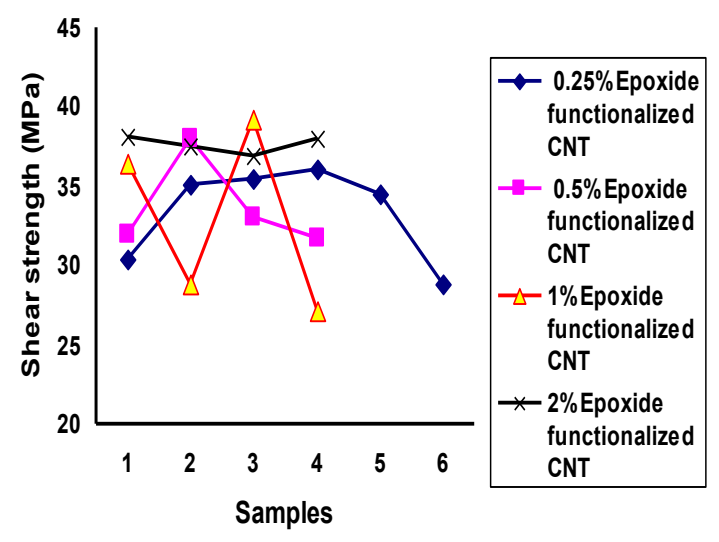

\begin{tabular}{|c|c|c|c|c|c|c|c|c|c|}
\hline & \multicolumn{9}{|c|}{ Sample } \\
\cline { 2 - 9 } & $\mathbf{B}$ & $\mathbf{A}_{0.25}$ & $\mathbf{A}_{0.5}$ & $\mathbf{A}_{1}$ & $\mathbf{A}_{2}$ & $\mathbf{E}_{0.25}$ & $\mathbf{E}_{0.5}$ & $\mathbf{E}_{1}$ & $\mathbf{E}_{2}$ \\
\hline $\begin{array}{c}\text { Mean ILSS } \\
\text { (MPa) }\end{array}$ & 32.71 & 33.46 & 36.53 & 34.11 & 32.88 & 34.81 & 33.53 & 34.82 & 37.63 \\
\hline
\end{tabular}

Table 3.3 Inter laminar shear strengths of no CNT, Amine functionalized CNT and Epoxide CNT/Cfiber/Epoxy composites

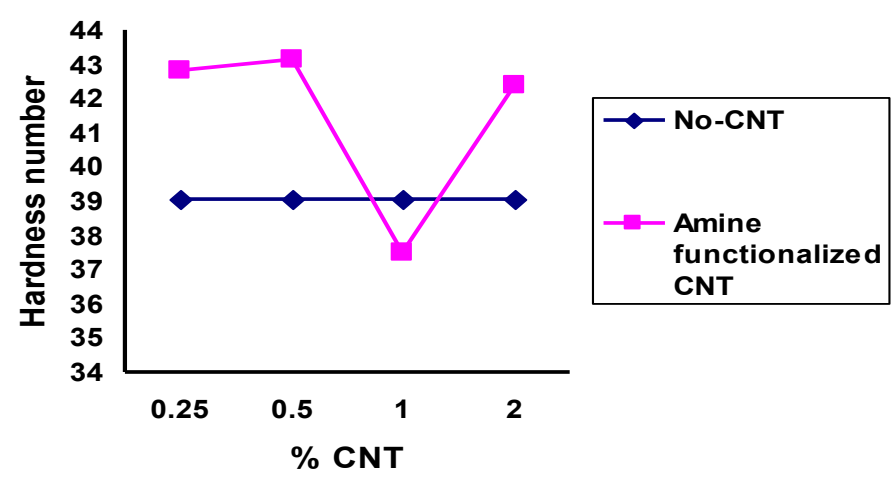

Figure 3.12 Re-Bound hardness number comparison between multi samples with same percentage of amine functionalized CNT/C-fiber/Epoxy composite

\section{Conclusion}

Serials of Amine-functionalized MWCNTs, Epoxide-functionalized MWCNTs and No-CNT contained C-fiber/Epoxy resin composites were prepared. The MWCNTs were dispersed in the matrix using ultrasonication technique. Based on the results presented in the previous sections, following general conclusions are drawn.

1. Compare to No-CNT, Epoxide functionalized CNT/C-fiber/epoxy composite, amine functionalized CNT/ Cfiber/epoxy composite giving better results.

2. From FTIR analysis, there is no proper functionalization occurred in the epoxide functionalized CNT. Due to that the epoxide functionalized composite samples are showing lesser values

3. In all testing methods shows that $\mathrm{A}_{0.5}$ samples give good results compared to others samples.

4. Amine functionalized CNTs are more suitable as reinforcements in epoxy systems than epoxide functionalized CNTs.

5. Standard deviation is large in test results of flexural.

6. Standard deviation is less in test results of ILSS.

\section{References}

[1] H. Chen, O. Jacobs, W. Wu, G. Rudiger and B. Schadel. Effect of dispersion method on tribological properties of carbon nanotu be reinforced epoxy resin composite. Polymer testing.2007:351-360.

[2] K.Q. Xiao, L.C. Zhang, and I.Zarudi. Mechanical and rheological properties of carbon nanotube-reinforced polyethylene composites. Composites science and technology. 2007:177-182. 
[3] P. C. Ma, J.K. Kim, and B.Z. Tang. Effects of Silane Functionalization on the Properties of Carbon Nanotube/Epoxy. Composites Science and Technology. Nanocomposites. 2007: 2965-2972.

[4] J. Shen, W. Huang, L.Wu, Y. Hu, and M. Ye. The reinforcement role of different amino-functionalized multi-walled carbon nanotubes in epoxy nanocomposites. Composites Science and Technology. 2007: 3041-3050.

[5] O. Jacobs, W. Xub, B. Scha, and W. Wu. Wear behaviour of carbon nanotube reinforced epoxy resin composites. Tribology Letters.2006. vol. 23.

[6] C.B. Mo, S.I. Cha, K.T. Kim, K.H. Lee and S.H. Hong, Fabrication of carbon nanotube reinforced alumina matrix nanocomposite by sol-gel process. Material science and engineering.2005: 124-128.

[7] W.J. Lee, S.E. Lee, and C.G. Kim. The mechanical properties of MWNT/PMMA nanocomposites fabricated by modified injection molding. Composite structure. 2006: 406-410.

[8] T.Liu, Y.Tong, and W.D. Zhang. Preparation and characterization of carbon nanotube/polyethermide nanocomposite films. Composites Science and Technology. 2006: 406-412.

[9] K.T.Lau, M.Lu, C.K. Lam, H.Y. Cheung, F.L. Sheng, and H.L. Li. Thermal and mechanical properties of single walled carbon nanotube bundle-reinforced epoxy nanocomposites: the role of solvent for nanotube dispersion. Composites Science and Technology. 2005: 719-725.

[10] J.Shen, W.Huang, L.Wu, Y.Hu and M. Ye. Thermo- physical properties of epoxy nanocomposite reinforced with aminofunctionalized multi walled carbon nanotubes. Composite. 2007: 1331-1336.

[11] A. Chatterjee, M.S. Islam. Fabrication and characterization of $\mathrm{TiO}_{2}$-epoxy nanocomposite. Material science and engineering. 2008: 574-585. 